\title{
Felipe B. Pedraza Jiménez, Rafael González Cañal y Elena E. Marcello (eds.), El universo cómico de Agustín Moreto (IV Centenario). XLI Jornadas de teatro clásico, Almagro 10, 11 y 12 de julio de 2018, Cuenca, Servicio de Publicaciones de la Universidad de Castilla-La Mancha, 2019 (Jornadas de teatro clásico, 41). 232 pp. ISBN: 978-84-9044-363-7
}

\section{Iván Gómez Caballero}

ORCID: https://orcid.org/0000-0001-8792-1088

Universidad de Castilla-La Mancha

ESPAÑA

ivan.gomez8@alu.uclm.es

[Hipogrifo, (issn: 2328-1308), 8.2, 2020, pp. 887-891]

Recibido: 03-08-2020 / Aceptado: 14-09-2020

DOI: http://dx.doi.org/10.13035/H.2020.08.02.55

En los últimos años, gracias a los proyectos de investigación de María Luisa Lobato (Universidad de Burgos), la crítica literaria se ha empezado a interesar por la figura y por el teatro de Agustín Moreto. El libro que hoy reseñamos es una recopilación de las conferencias y coloquios de las XLI Jornadas de teatro clásico de Almagro, El universo cómico de Agustín Moreto (IV Centenario), celebradas durante el 10 y 12 de julio de 2018 en el Palacio de los condes de Valdeparaíso de Almagro 
(Ciudad Real). Recientemente, han sido editadas por Felipe B. Pedraza Jiménez (Universidad de Castilla-La Mancha), Rafael González Cañal (Universidad de CastiIla-La Mancha), y Elena E. Marcello (Università degli Studi Roma Tre) y publicadas por el Servicio de Publicaciones de la Universidad de Castilla-La Mancha.

En este evento científico, se reunieron los principales expertos sobre Agustín Moreto (1618-1669), a excepción de María Luisa Lobato, que no pudo asistir por motivos personales. Prescindiendo de las «Crónicas de los coloquios» y «Libros en escena», las actas abordan temas monográficos sobre su teatro, que, con ocasión del cuarto centenario de su nacimiento, el comité organizador y científico de las XLI Jornadas de teatro clásico de Almagro, quiso rendirle este especial homenaje. Como viene siendo habitual desde hace ya varias ediciones, Felipe B. Pedraza Jiménez, por entonces codirector de las Jornadas de teatro clásico de Almagro y hoy todavía catedrático de Literatura Española de la Universidad de Castilla-La Mancha, ofrece unas palabras preliminares al lector. Posteriormente, se incrusta el programa de las XLI Jornadas de teatro clásico de Almagro. Las actas están divididas en cinco bloques temáticos: «El comediógrafo y sus recursos» (pp. 17-114), «Cuestiones métricas» (pp. 117-151), «Moreto en el tiempo» (pp. 155-198), «Crónica de los coloquios» (pp. 201-222) y, por último, «Libros en escena» (pp. 225-232).

En primer lugar, «El comediógrafo y sus recursos aborda la comicidad en el teatro de Moreto» incluye los siguientes artículos: «Comicidad y transgresión en el teatro de Agustín Moreto» (pp. 17-42) de María Rosa Álvarez Sellers, «Tres Moretos en uno: Multiplicidad cómica en el autor madrileño» (pp. 43-62) de Delia Gavela García, «Algunos recursos cómicos de Moreto en Amor y obligación» (pp. 63-86) de Carmen Pinillos Salvador, «La confusión de identidades en la comedia palatina de Moreto: El caso de Lo que puede la aprensión» (pp. 87-100) de Jéssica Castro Rivas y, por último, «Humor y comicidad en el teatro breve de Moreto» (pp. 101-114) de Abraham Madroñal Durán. Álvarez Sellers (Universidad de Valencia) inaugura, por tanto, las actas y aborda el estudio del teatro moretiano desde la perspectiva de la comicidad, ahondando en el análisis cómico de los criados de Moreto, que transgreden el lenguaje dramático y situaciones habituales de la comedia de los Siglos de Oro. La investigadora valenciana sostiene que lo curioso del teatro de Moreto es dotar a los personajes de cierto psicologismo para integrarlos en la obra con situaciones divertidas en las que se dirigen al público. Gracias a estas técnicas, Moreto consiguió gran éxito, tanto en España, como en Hispanoamérica.

Delia Gavela García (Universidad de la Rioja) profundiza en el estudio de la comicidad moretiana, al igual que Álvarez Sellers, pero centrándose en tres comedias: Trampa adelante, El hijo pródigo y De fuera vendrá quien de casa nos echará. El artículo se centra en la figura del gracioso - personaje marcado por la vulgaridad y rusticidad, propia de pastores y criados-, aspectos cómicos del teatro de Moreto y también en rasgos estilísticos y temáticos. Por otra parte, Carmen Pinillos Salvador (Universidad de Navarra) analiza Amor y obligación, una comedia desconocida de Agustín Moreto. Examina temas como la comicidad, la trama, personajes y la importancia de rasgos estilísticos como la homofonía y morfológicos como los neologismos para resaltar la comicidad. 
Lo que puede la aprensión es otra de las comedias analizadas en este bloque. Jéssica Castro Rivas (Universidad de Chile) realiza una definición y un marco genérico de esta comedia palatina, donde inspecciona la confusión de identidades de esta comedia a partir de la alteración de la identidad de los personajes, el disfraz social y ciertos motivos, como recuperar el honor y alcanzar un determinado fin con una finalidad cómica. El artículo de Abraham Madroñal Durán (Universidad de Ginebra) es el último de este primer bloque. El profesor Madroñal, especialista en entremeses y teatro breve de Quiñones de Benavente, investiga la comicidad en el teatro breve de Agustín Moreto, que escribió varias loas, bailes y entremeses. Elabora un panorama con algunos de sus entremeses como El poeta, Entremés de las fiestas de palacio, Baile de Lucrecia y Tarquino, La Pendereca, El reloj y los órganos, Alcolea, El cortacaras y La mariquita, entre otros. Analiza las técnicas metaliterarias y metateatrales, el ritmo, la gestualidad, movimiento escénico, la onomástica ridiculizante, los disparates y la comicidad de estos entremeses. Concluye este atrayente estudio con entremeses de dudosa atribución como Las burlas de Pantoja y el doctor y La condesa fregatriz, relacionados con Las travesuras de Pantoja, atribuida también a Antonio Enríquez Gómez y con El lindo don Diego, respectivamente.

En segundo lugar, las actas también abordan cuestiones métricas en el segundo bloque: por un lado, con «Estructuras sonoras en la comedia cómica de Moreto: Reflexiones a partir de Lo que puede la aprensión» (pp. 117-126) de Simón Kroll y «Espacio y métrica en las comedias de Agustín Moreto: Los casos de El desdén con el desdén y De fuera vendrá quien de casa nos echará» (pp. 127-151) de Débora Vaccari. Simón Kroll (Universidad de Heidelberg) realiza un refrescante análisis métrico de Lo que puede la aprensión para demostrar que el uso de asonancias tiene, al igual que en el teatro de Pedro Calderón de la Barca, una carga semántica. Para ello, expone su teoría semántico-dramática sobre El monstruo de los jardines de Calderón de la Barca y, posteriormente, analiza Lo que puede la aprensión de Agustín Moreto, en la que el investigador alemán señala que el uso de asonancias en -i se puede vincular con las pasiones amorosas de la obra. Kroll sostiene que hay una estrecha vinculación entre la métrica aurea y la semántica de la obra e invita a realizar un estudio métrico-semántico en la obra de Moreto con una nueva metodología a los investigadores del teatro de los Siglos de Oro.

Debora Vacari (Sapienza Università di Roma) analiza la métrica y el espacio de El desdén con el desdén y De fuera vendrá quien de casa nos echará. Para la investigadora italiana, hay una estrecha conexión entre métrica y espacio dramático en teatro de los siglos de Oro. El desdén con el desdén es una obra polimétrica porque la trama se desarrolla en espacios interiores, fundamentalmente el palacio del conde de Barcelona, el jardín y los aposentos de Diana. Por otra parte, De fuera vendrá quien de casa nos echará desarrolla la acción en espacios interiores como Madrid, las gradas de san Felipe y la casa de Cecilia, por tanto, hay poca variedad de metros, reduciendo la polimetría al desarrollarse en espacios exteriores.

El tercer bloque, «Moreto en el tiempo», incrusta los siguientes artículos: «El decreto del cielo: Moreto refundido por un sefardí de Ámsterdam» (pp. 155-171) de Félix Blanco Campos, «Los felices años 60: El desdén con el desdén» (pp. 173-180) 
de Jesús Cracio y «Fanfarrones y lindos desde la antigüedad clásica hasta nuestros días: El lindo don Diego de Morboria Teatro» (pp. 181-198) de Miriam Martínez Gutiérrez. Según Félix Blanco Campos (Universidad de Valladolid), hay un paralelismo claro y evidente entre El decreto del cielo de Fundam y Amor y obligación de Agustín Moreto, puesto que el autor judío imitó y copió versos enteros de Agustín Moreto. Se añade en este minucioso y exhaustivo análisis una tabla comparativa de ambos textos. Fundam se aleja del texto de Amor y obligación en cierto sentido, ya que reduce la obra a un acto y se queda con dos protagonistas y el conflicto principal. Blanco Campos observa en qué difieren ambas obras en cuanto a temática y argumento.

El director escénico Jesús Cracio recuerda sus años de juventud como director del Área Teatral del Instituto de la Juventud (INJUVE) y, particularmente, la representación cómica de El desdén con el desdén de Agustín Moreto. Resalta aspectos peculiares de la obra como la configuración protofeminista del personaje de Diana y también aboga por el recitado natural del verso clásico sin que resulte forzoso. Al representar la obra, Cracio incluyó música del momento y convirtió la obra en casi un musical incluyendo bailes. En definitiva, transgredió el texto, lo cual gustó mucho al público y a la crítica. Miriam Martínez Gutiérrez (Universidad Complutense de Madrid) aborda brevemente los orígenes y antecedentes del personaje del figurón del siglo XVII, presentes ya en el teatro latino de Plauto, para centrarse en las representaciones de El lindo don Diego de 2004 y 2017 de la compañía Morboria Teatro. Estudia la adaptación del texto en cuanto a escenografía, personajes y vestuario. La compañía de Eva del Palacio acomodó los espacios de El lindo don Diego a los años 20 del siglo pasado y alteró el sexo de algunos personajes, lo que ganó el beneplácito de la joven burgalesa. En definitiva, Martínez Gutiérrez enaltece la adaptación del texto de esta conocida compañía.

Tras estos estudios, Milagros Rodríguez Cáceres narra las crónicas de los coloquios que tuvieron lugar en las XLI Jornadas de teatro clásico de Almagro: «Coloquio sobre la puesta en escena de las comedias moretianas» (pp. 201-207), «Coloquio sobre El burlador de Sevilla por la Compañía Nacional de Teatro Clásico» (pp. 209-215) y «De fuera vendrá quien de casa nos echará de Agustín Moreto por Morboria Teatro» (pp. 217-222). En el primer coloquio sobre experiencias de las puestas en escena, la fortuna escénica y la proyección internacional de Agustín Moreto, participaron Felipe B. Pedraza, Josefina Molina (guionista y directoria de cine, televisión y teatro), Rafael Pérez Sierra (iniciador de las Jornadas y catedrático de la Escuela Superior de Canto) y Enrico di Pastena (catedrático de la Universidad de Pisa). Seguidamente, encontramos el segundo coloquio, en el que también participó Felipe B. Pedraza, junto a Borja Ortiz de Gondra y Raúl Prieto, ambos egresados de la Real Escuela Superior de Arte Dramático de Madrid (RESAD), sobre la representación teatral de El burlador de Sevilla. Según deja constancia Rodríguez Cáceres, deducimos que este coloquio causó gran interés al público de aquella tarde por las constantes intervenciones de los asistentes. Finalmente, participaron en el tercer y último coloquio sobre De fuera vendrá quien de casa nos echará, Felipe B. Pedraza, que elogió la puesta en escena de esta obra, Eva del Palacio y Fernando Aguado, ambos actores de la compañía Morboria Teatro. Este coloquio trató, entre otros temas, el mantenimiento económico de la compañía gracias a las subven- 
ciones y, por supuesto, el interés de la compañía por el teatro de Agustín Moreto. «Libros en escena», el último bloque de estas actas, recoge una reseña de Felipe B. Pedraza Jiménez (pp. 225-227) de las actas de las anteriores jornadas, Drama y teatro en tiempos de Carlos I (1517-1556), que se celebraron durante el 10 y 12 de julio de 2017, y un artículo de Álvaro Tato y Mar Zubieta, sobre «Cuadernos de Teatro Clásico», revista científica de la Compañía Nacional de Teatro Clásico.

Las XLI Jornadas de teatro clásico trataron, pues, temas muy variados, como la comicidad, la métrica y la fortuna escénica de Agustín Moreto, y reunieron a investigadores internacionales como Debora Vaccari y Simon Kroll, y a dramaturgos y a actores, como Eva del Palacio, Fernando Aguado, Borja Ortiz de Gondra y Raúl Prieto. El público participó, sin lugar a duda, en los coloquios teatrales que fueron interesantes. Las publicaciones de estas actas monográficas son muy valiosas para que la comunidad científica pueda seguir investigando sobre Agustín Moreto, al mismo tiempo que divulgan su figura y su teatro entre el público más joven, que está empezando a conocer otros dramaturgos más allá de Calderón de la Barca, Tirso de Molina y Lope de Vega, como Rojas Zorrilla, Vélez de Guevara, Moreto, Enríquez Gómez, Godínez y Mira de Amescua, entre otros. 